\title{
Heparin-Induced Thrombocytopenia in Critically III Patients
}

\author{
Theodore E. Warkentin, MD ${ }^{1,2}$ \\ ${ }^{1}$ Department of Pathology and Molecular Medicine, Michael G. \\ DeGroote School of Medicine, McMaster University, Hamilton, \\ Ontario, Canada \\ 2 Department of Medicine, Michael G. DeGroote School of Medicine, \\ McMaster University, Hamilton, Ontario, Canada

\begin{abstract}
Address for correspondence Theodore E. Warkentin, MD, Hamilton Regional Laboratory Medicine Program, Room 1-270B, Hamilton Health Sciences, Hamilton General Site, 237 Barton St. East, Hamilton, Ontario L8L 2X2, Canada (e-mail: twarken@mcmaster.ca).
\end{abstract}

Semin Thromb Hemost 2015;41:49-60.

\begin{abstract}
Keywords

- adrenal hemorrhagic necrosis

- disseminated intravascular coagulation

- heparin-induced thrombocytopenia

- shock liver

Many critically ill patients receive heparin, either before intensive care unit (ICU) admission (e.g., postcardiac surgery), for prophylaxis/treatment of thrombosis, for hemodialysis/filtration, or even incidentally (e.g., flushing of intravascular catheters), and are therefore at risk for developing immune heparin-induced thrombocytopenia (HIT), a prothrombotic drug reaction caused by platelet-activating antiplatelet factor 4 (PF4)/heparin antibodies. However, HIT explains at most 1 in 100 thrombocytopenic ICU patients (HIT frequency $0.3-0.5 \%$ vs. $30-50 \%$ background frequency of ICU-associated thrombocytopenia), and most patients who form anti-PF4/heparin antibodies do not develop HIT; hence, HIT overdiagnosis often occurs. This review discusses HIT-related issues relevant to ICU patients, including how to (1) distinguish HIT both clinically and serologically from non-HIT-related thrombocytopenia; (2) recognize HIT-mimicking disorders, such as the acute disseminated intravascular coagulation (DIC)/liver necrosislimb necrosis syndrome; (3) prevent HIT in the ICU through use of low-molecular-weight heparin; and (4) treat HIT, including awareness of "PTT confounding" when anticoagulating patients with DIC.
\end{abstract}

Heparin-induced thrombocytopenia (HIT) is an adverse drug reaction caused by platelet-activating immunoglobulin $G$ (IgG) antibodies ${ }^{1}$ that recognize multimolecular platelet factor 4 (PF4)/heparin complexes ${ }^{2,3}$ (for review ${ }^{4,5}$ ). HIT is highly prothrombotic: approximately 50 to $75 \%$ of patients with serologically confirmed HIT develop venous or arterial thrombosis, ${ }^{6-8}$ which per one analysis corresponded to a relative risk for clinically relevant thrombosis of 12.0 (95\% confidence interval $[\mathrm{CI}], 7.0-20.6 ; p<0.0001)^{9}{ }^{9}$

Unusually severe or atypical thrombosis is a hallmark for HIT. Lower-limb deep-vein thrombosis (DVT) is often bilateral, ${ }^{7,8}$ and approximately half of patients with DVT exhibit pulmonary embolism (PE). ${ }^{6}$ HIT-associated ischemic limb necrosis due to arterial or venous/microvascular

published online January 15, 2015
Issue Theme Thrombosis and Hemostasis Issues in Critically III Patients; Guest Editor, Marcel Levi, MD, PhD. thrombosis is relatively common, ${ }^{10}$ and approximately $5 \%$ of patients with HIT evince ischemic limb injury. ${ }^{11}$ Further, diagnostic confusion can result between certain forms of HIT-associated venous limb ischemia versus non-HIT-related disseminated intravascular coagulation (DIC) complicated by symmetrical peripheral gangrene, as both conditions feature thrombocytopenia, consumptive coagulopathy, and acral limb ischemic necrosis despite arterial pulses.

HIT is relatively uncommon in the critically ill patientexplaining at most 1 in 100 patients with intensive care unit (ICU)-associated thrombocytopenia ${ }^{12}$-and the clinician's challenge is to distinguish the (relatively) uncommon patient with HIT among the many without.

Copyright (C) 2017 by Thieme Medical Publishers, Inc., 333 Seventh Avenue, New York, NY 10001, USA.

License terms Tel: +1(212) 584-4662. 


\section{Heparin-Induced Thrombocytopenia Is a Clinical-Pathological Disorder}

A diagnosis of HIT will be made most accurately if HIT is viewed as a "clinical-pathological" syndrome, ${ }^{4,5,13}$ in which (1) the patient exhibits a clinical profile broadly consistent with HIT, for example, thrombocytopenia and/or thrombosis bearing a temporal relationship with a preceding immunizing exposure to heparin ("clinical") and (2) the patient's serum (or plasma) is shown to contain heparin-dependent platelet-activating antibodies ("pathological"). One recommended framework ${ }^{14}$ for defining HIT is a clinical picture judged to be at least intermediate probability (e.g., scoring at least 4 points in the 4 Ts pretest probability scoring system ${ }^{15-17}$ ) and detectability of heparindependent, platelet-activating antibodies (e.g., positive serotonin-release assay (SRA) ${ }^{18,19}$ or heparin-induced platelet activation test ${ }^{20,21}$ with a corroborating positive test for anti-PF4/ heparin antibodies by a PF4-dependent immunoassay, most often an enzyme immunoassay (EIA). ${ }^{22}$

\section{Clinical Picture of Heparin-Induced Thrombocytopenia: 4Ts Perspective}

To distinguish HIT from non-HIT thrombocytopenic disorders, it is important to appreciate the clinical picture of HIT, here viewed through a widely used scoring system, the 4Ts (- Table 1). ${ }^{15-17}$

\section{Thrombocytopenia}

The first " $T$," Thrombocytopenia, is characterized by largemagnitude declines in the platelet count (usually, at least 50\%) that, however, do not usually reach very low values. Indeed, in the 4Ts, 0 points are given for a platelet count value $<10 \times 10^{9} / \mathrm{L}$, and only 1 point for a platelet count result between 10 and $19 \times 10^{9} / \mathrm{L}$, whereas a $>50 \%$ platelet count fall with nadir $\geq 20 \times 10^{9} / \mathrm{L}$ scores as 2 points. (Only $\sim 10 \%$ of patients with HIT develop a platelet count nadir $<20 \times 10^{9} / \mathrm{L}^{23}$ ) This (usual) lack of very severe thrombocytopenia probably reflects the fundamental platelet-activating nature of HIT, as other platelet-activating disorders such as DIC are also characterized by moderate thrombocytopenia, whereas destructive thrombocytopenia caused by platelet-reactive autoantibodies or drug-dependent antibodies often reach platelet count nadirs $<20 \times 10^{9} /$ L. $^{24}$ Therefore, the magnitude of the platelet count fall is usually not helpful in distinguishing HIT from non-HIT thrombocytopenia in critically ill patients.

\section{Timing}

In contrast, the second " $T$," Timing of onset of thrombocytopenia (or thrombosis) in relation to a proximate (preceding) heparin exposure, is much more useful. Most critically ill patients-whether admitted to ICU immediately postsurgery, or directly from the community with acute illness-evince early-onset thrombocytopenia. Indeed, even with elective surgery, early postoperative thrombocytopenia is expected, with nadir platelet counts between postoperative days 1 and 4 (median, day 2 ). ${ }^{25}$

In contrast, - Fig. 1 shows "typical-onset" HIT developing in a critically ill postcardiac surgery patient: here, the unexpected thrombocytopenia that began 5 days postsurgery-with

Table 1 4Ts scoring system

\begin{tabular}{|c|c|c|c|}
\hline & \multicolumn{3}{|c|}{ Points $(0,1$, or 2 for each of four categories: maximum possible score $=8)$} \\
\hline & 2 & 1 & 0 \\
\hline Thrombocytopenia & $>50 \%$ platelet fall to nadir $\geq 20$ & $\begin{array}{l}30-50 \% \text { platelet count fall } \\
\text { (or }>50 \% \text { directly resulting } \\
\text { from surgery); or nadir } 10-19\end{array}$ & $\begin{array}{l}<30 \% \text { platelet fall; or } \\
\text { nadir }<10\end{array}$ \\
\hline $\begin{array}{l}\text { Timing a of platelet count } \\
\text { fall, thrombosis, or other } \\
\text { sequelae ( } 1 \text { st day of putative } \\
\text { immunizing exposure to } \\
\text { heparin = day } 0 \text { ) }\end{array}$ & $\begin{array}{l}\text { Days } 5-10 \text { onset }^{\mathrm{a}} \text { (typical/ } \\
\text { delayed-onset } \mathrm{HIT} \text { ); or } \leq 1 \text { day } \\
\text { (with recent heparin exposure } \\
\text { within past } 30 \text { days (rapid-onset } \\
\text { HIT) }\end{array}$ & $\begin{array}{l}\text { Consistent with days } 5-10 \\
\text { fall, but not clear (e.g., miss- } \\
\text { ing platelet counts); or, } \leq 1 \\
\text { day (heparin exposure within } \\
\text { past } 31-100 \text { days) (rapid- } \\
\text { onset HIT); or, platelet fall } \\
\text { after day } 10\end{array}$ & $\begin{array}{l}\text { Platelet count fall } \leq 4 \text { days } \\
\text { (unless picture of rapid- } \\
\text { onset HIT-see two left boxes) }\end{array}$ \\
\hline $\begin{array}{l}\text { Thrombosis or other se- } \\
\text { quelae (e.g., skin lesions, } \\
\text { anaphylactoid reactions) }\end{array}$ & $\begin{array}{l}\text { Proven new thrombosis; or skin } \\
\text { necrosis (at injection site); or } \\
\text { postintravenous heparin bolus } \\
\text { anaphylactoid reaction }\end{array}$ & $\begin{array}{l}\text { Progressive or recurrent } \\
\text { thrombosis; or erythematous } \\
\text { skin lesions (at injection site); } \\
\text { or suspected thrombosis (not } \\
\text { proven); hemofilter } \\
\text { thrombosis }\end{array}$ & None \\
\hline $\begin{array}{l}\text { OTher cause for } \\
\text { thrombocytopenia }\end{array}$ & $\begin{array}{l}\text { No explanation for platelet } \\
\text { count fall is evident }\end{array}$ & $\begin{array}{l}\text { Possible other cause is } \\
\text { evident }\end{array}$ & $\begin{array}{l}\text { Definite other cause is } \\
\text { present }\end{array}$ \\
\hline
\end{tabular}

Abbreviation: HIT, heparin-induced thrombocytopenia.

Note: The scoring system shown above includes minor modifications compared with previously published versions.

${ }^{a}$ First day of immunizing heparin exposure considered day 0 ; the day the platelet count begins to fall is considered the day of onset of thrombocytopenia (it generally takes 1-3 more days until an arbitrary threshold that defines thrombocytopenia is passed). Usually, heparin administered at or near surgery is the most immunizing situation (i.e., day 0 ). 


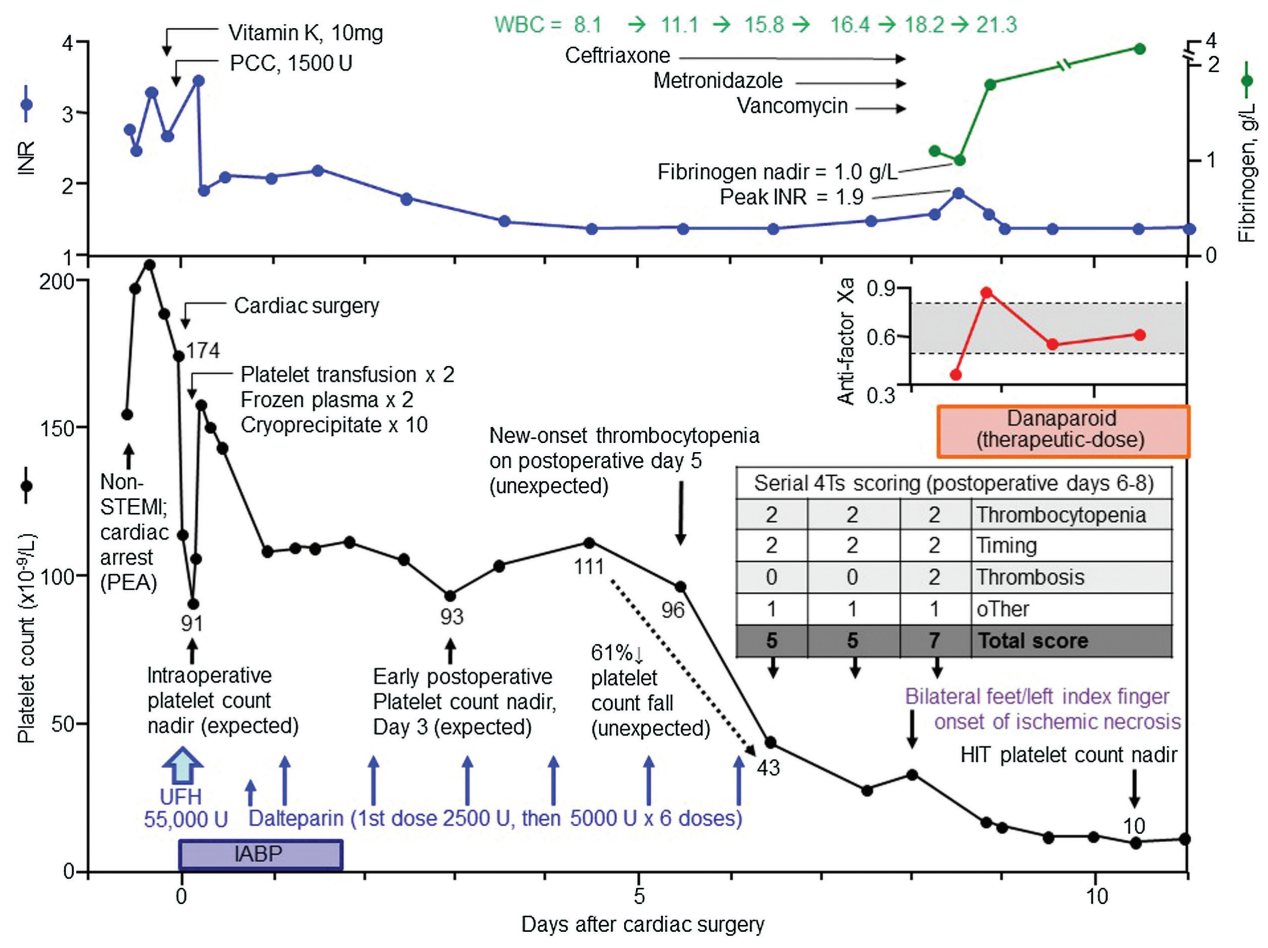

Fig. 1 Clinical picture of HIT-associated DIC. A 72-year-old man developed HIT beginning on postoperative day 5 following emergency coronary artery bypass surgery. (Despite preoperative administration of vitamin $\mathrm{K}$ and 4 -factor prothrombin complex concentrate-to reverse warfarin anticoagulation-postoperative coagulopathy/bleeding required treatment with platelet, frozen plasma, and cryoprecipitate transfusions.) Initially, the unexpected thrombocytopenia was attributed to infection (rising white blood count); however, when multiple limb ischemia developed on postoperative day 8 , HIT became the leading diagnosis, and therapeutic-dose anticoagulation with danaparoid was started. The patient tested strongly positive for HIT antibodies by both SRA ( $95 \%$ serotonin-release at 0.1 , and $0.3 \mathrm{IU} / \mathrm{mL}$ UFH [normal, $<20 \%$ serotoninrelease] with inhibition to $1 \%$ serotonin-release at $100 \mathrm{IU} / \mathrm{mL}$ UFH); moreover, $95 \%$ serotonin release was also observed at $0 \mathrm{IU} / \mathrm{mL}$ UFH (buffer control). The anti-PF4/heparin IgG-specific EIA also tested strongly positive ( 2.59 units of optical density; normal $<0.45$ units). This patient also developed severe HIT-associated DIC, as shown by: (1) hypofibrinogenemia (fibrinogen nadir, $1.0 \mathrm{~g} / \mathrm{L}$ ), (2) elevated international normalized ratio (peak INR, 1.9), and (3) marked increase in fibrin D-dimer (> 20,000 FEU $\mu \mathrm{g} / \mathrm{L}$; normal $<500 \mathrm{FEU} \mu \mathrm{g} / \mathrm{L}$ ). Although danaparoid helped control the DIC (normalization of the INR and fibrinogen), irreversible limb ischemic necrosis was apparent, and the patient died after life support was withdrawn on postoperative day 11 . The inset illustrates application of the 4Ts scoring system, whereby an initial score of 5 points (intermediate probability) on postoperative day 6 increased to 7 points (high probability) on day 8 when limb ischemia developed. DIC, disseminated intravascular coagulation; EIA, enzyme immunoassay; FEU, fibrinogen equivalent units; HIT, heparin-induced thrombocytopenia; IABP, intraaortic balloon pump; IgG, immunoglobulin G; INR, international normalized ratio; non-STEMI, non-ST elevation myocardial infarction; PCC, prothrombin complex concentrate; PEA, pulseless-electrical activity; PF4, platelet factor4; SRA, serotonin-release assay; WBC, white blood count; U, units; UFH, unfractionated heparin.

intraoperative exposure to unfractionated heparin (UFH) and postoperative thromboprophylaxis with low- molecularweight heparin (LMWH)-places HIT firmly in the differential diagnosis. By day 6, the 4Ts score was 5 points (intermediate probability score); however, the clinicians suspected septicemia (due to increasing white blood count), and HIT was only considered 2 days later when limb ischemia began ( $4 \mathrm{Ts}=7$ points [high probability score]). Laboratory studies also showed concomitant HIT-associated DIC.

\section{Point Immunization}

Postoperative HIT exhibits a characteristic timeline (all values in parentheses represent median values): early postoperative thrombocytopenia (onset, day 0 ) followed by expected postoperative (non-HIT) thrombocytopenic nadir (day 2) followed by initial detection of anti-PF4/heparin antibodies (day 4) followed by the beginning of the HIT-associated platelet count fall (day 6) followed by progressive platelet count decline to $>50 \%$ (day 8 ), often complicated by symptomatic throm- bosis (day 10). ${ }^{26}$ This characteristic timeline infers a preceding "point immunization," where intra-/early postoperative heparin exposure, coinciding with perioperative PF4 release from activated platelets, together with inflammation, trigger the anti-PF4/heparin immune response. ${ }^{5}$

\section{Typical, Rapid, Delayed, and Spontaneous Onset of HIT}

The platelet count fall usually begins between days 5 and 10 (inclusive) following the immunizing heparin exposure (day $0{ }^{27}$ For a patient recently exposed to heparin (within the previous several weeks or months), and who therefore already has circulating HIT antibodies, resumption of heparin can trigger an abrupt platelet count fall, termed "rapid-onset" HIT. ${ }^{27}$ Here, the characteristic association with recent (but not remote) preceding heparin exposure reflects the unusual transience of HIT antibodies, which become undetectable a median of 50 to 80 days (depending on the assay performed) following an episode of HIT. ${ }^{27}$ The transience of HIT antibodies is striking: we have observed patients whose antibody 
levels waned-along with platelet count recovery-even as heparin was continued. ${ }^{28}$ Of note, any time that HIT antibodies are actively being generated (whether de novo or recurrent) requires at least 5 days postimmunizing heparin exposure (or reexposure) before HIT-related thrombocytopenia can begin. $^{29}$

"Delayed-onset" HIT refers to HIT that begins ${ }^{30}$ or worsens ${ }^{4,31}$ after stopping heparin. These patients can have unusually severe or persisting thrombocytopenia, often accompanied by overt (decompensated) DIC. In such patients, the SRA shows very strong serum-induced platelet activation even in the absence of heparin. ${ }^{30,31}$ The ability of such highly pathogenic antibodies to activate platelets directly helps explain why the patient's thrombocytopenia can begin or worsen without further heparin being given.

"Spontaneous" HIT syndrome indicates a disorder clinically and serologically indistinguishable from HIT except for the absence of a proximate heparin exposure. ${ }^{32,33}$ Approximately half of these patients developed this disorder postorthopedic surgery (during prophylaxis with warfarin or a new oral anticoagulant) $)^{33,34}$ and the remaining usually postinfection (perhaps, joint cartilage ${ }^{33}$ or negatively charged bacterial walls ${ }^{35}$ provide a template for PF4-dependent immunization). Postorthopedic surgery spontaneous HIT syndrome appears to be a high-risk situation for adrenal hemorrhagic necrosis, ${ }^{34,36}$ which if bilateral leads to life-threatening adrenal failure. Sera from spontaneous HIT patients also exhibit strong platelet-activating properties in the absence of heparin. ${ }^{33}$

\section{Thrombosis}

The third " $T$," Thrombosis (or other clinical sequelae of HIT), is an important diagnostic clue for HIT. This is because HIT is strongly associated with thrombosis, both in absolute and relative terms ${ }^{6-9}$; in one study, the relative risk for thrombosis $(\sim 12)$ reflected a frequency of venous thromboembolism in HIT of approximately $50 \%$ versus a non-HIT background rate of approximately $4 \%{ }^{9}$ Although HIT-associated thrombosis occurs at a median of day 10 , the range is wide, and many patients develop symptomatic thrombosis at the beginning of the HIT-associated platelet count fall, ${ }^{37,38}$ even before criteria for thrombocytopenia are met.

Venous predominates over arterial thrombosis. Most often, lower-limb DVT is observed (sometimes bilateral), whereas upper-limb DVT is strongly associated with intravascular catheter use. ${ }^{39}$ Severe HIT-associated DIC can be complicated by microvascular thrombosis (e.g., acral ischemic necrosis despite palpable pulses) (-Fig. 1). Warfarin therapy-resulting in acquired severe protein $\mathrm{C}(\mathrm{PC})$ depletion-is a major risk factor for venous limb gangrene, ${ }^{40,41}$ and thus warfarin is contraindicated during the acute (thrombocytopenic) phase of HIT (and vitamin $\mathrm{K}$ is indicated if warfarin has already been given). ${ }^{11,42}$ Large-artery thrombosis secondary to platelet-rich "white clots"-the classic picture of HIT recognized $>40$ years ago ${ }^{43}$-usually requires urgent thromboembolectomy for limb salvage. ${ }^{44}$ Miscellaneous features of HIT $^{10}$ include unusual sites of venous thrombosis (adrenal vein thrombosis leading to hemorrhagic necro- sis, ${ }^{34,36,38}$ mesenteric vein thrombosis, cerebral venous/dural sinus thrombosis ${ }^{45}$ ), necrotizing skin lesions at heparin injection sites ${ }^{46}$ (and rarely at noninjection sites ${ }^{10}$ ), and anaphylactoid reactions ${ }^{47}$ that begin within 30 minutes of an intravenous UFH bolus ${ }^{48}$ or within 2 hours of subcutaneous injection of $\mathrm{LMWH}^{49}$

\section{HIT-Associated Disseminated Intravascular Coagulation} Approximately 10 to $20 \%$ of patients who develop HIT evince overt (decompensated) DIC, as shown by an otherwise unexplained increased international normalized ratio (INR) or absolute/relative hypofibrinogenemia. ${ }^{10}$ The pathogenesis includes procoagulant, platelet-derived microparticles ${ }^{24}$ and monocyte activation. ${ }^{50}$ Patients often exhibit unusually severe thrombocytopenia and microthrombosis (e.g., acral limb ischemia), and patient serum demonstrates strong platelet activation even in the absence of heparin (-Fig. 1).

\section{Other (Differential Diagnosis)}

The fourth "T," OTher cause(s) of thrombocytopenia, is also relatively unhelpful in the ICU, since virtually all critically ill patients have plausible non-HIT explanations for their thrombocytopenia. Prospective studies in critically ill patients have found a frequency of thrombocytopenia of approximately 30 to $50 \%{ }^{12,51,52}$ Accordingly, one might score 0 or 1 point (never 2 points) when evaluating this 4Ts criterion in a critically ill patient.

HIT-Mimicking Disorder: Acute DIC/Hepatic Necrosis-Limb Necrosis Syndrome

Certain HIT-mimicking disorders have been recognized. ${ }^{53}$ For example, a postcardiac surgery patient who develops acuteonset and persisting thrombocytopenia, DIC, and multiple organ failure, and who then develops symmetrical peripheral gangrene (i.e., two- or four-limb acral ischemic necrosis) can be misdiagnosed as HIT, particularly since postcardiac surgery patients often test EIA positive. The author has reported several critically ill patients who have developed multiple limb ischemic necrosis postcardiac surgery and has noted the combination of DIC with preceding "shock liver" (also termed "acute hepatic necrosis" or "ischemic hepatitis"). ${ }^{52-55}$ The pathogenesis of microvascular thrombosis reflects profoundly disturbed procoagulant-anticoagulant balance, for example, marked increased in thrombin generation with concomitant severely reduced antithrombin (AT) and PC levels, ${ }^{54}$ and is analogous to warfarin-induced venous limb gangrene complicating HIT (-Table 2 ).

- Table 3 summarizes aggregate data for 15 non-HIT patients who developed microvascular ischemic limb necrosis ("gangrene with pulses") complicating acute DIC; none was given warfarin before onset of limb ischemia. All patients evinced the clinical picture of symmetrical peripheral gangrene, with lower limbs characteristically involved, but fingers/hands also affected in approximately one-third of cases. A preceding clinical picture of "shock liver" was seen in 14/15 (93\%) patients, consistent with a pathogenic role of natural anticoagulant depletion associated with severe hepatic dysfunction. 
Table 2 Ischemic limb necrosis with palpable/Doppler-identifiable pulses: comparison of two thrombocytopenic syndromes

\begin{tabular}{|c|c|c|}
\hline Feature & $\begin{array}{l}\text { HIT-associated DIC (incl. warfarin- } \\
\text { induced venous limb gangrene) }\end{array}$ & $\begin{array}{l}\text { Acute DIC/hepatic necrosis-limb } \\
\text { necrosis syndrome }\end{array}$ \\
\hline $\begin{array}{l}\text { Onset of } \\
\text { thrombocytopenia }\end{array}$ & $\begin{array}{l}\text { 5-10 days after immunizing heparin } \\
\text { exposure }\end{array}$ & $\begin{array}{l}\text { Usually }<4 \text { days after preceding heparin } \\
\text { exposure (early-onset and persisting } \\
\text { thrombocytopenia) }\end{array}$ \\
\hline Onset of limb ischemia & $\begin{array}{l}\text { 2-5 days after onset of HIT (or warfarin } \\
\text { treatment of HIT) }\end{array}$ & $\begin{array}{l}2-5 \text { days after onset of acute liver } \\
\text { dysfunction }\end{array}$ \\
\hline $\begin{array}{l}\text { Concomitant large-vessel } \\
\text { thrombosis (e.g., DVT) }\end{array}$ & Usually yes & Usually no \\
\hline HIT antibodies & Strong positive EIA and SRA & $\begin{array}{l}\text { Negative or weak-/moderate-positive } \\
\text { tests }\end{array}$ \\
\hline Liver function & Normal or minor impairment & $\begin{array}{l}\text { Severely impaired, with preceding "shock } \\
\text { liver" (transaminitis) although severe } \\
\text { hepatobiliary dysfunction can also be } \\
\text { seen }\end{array}$ \\
\hline $\begin{array}{l}\text { Explanation for increased } \\
\text { thrombin generation }\end{array}$ & $\begin{array}{l}\text { HIT antibody-induced platelet and } \\
\text { monocyte activation }\end{array}$ & $\begin{array}{l}\text { Multiple triggers, e.g., cardiogenic or } \\
\text { hemorrhagic shock, septicemia, } \\
\text { fungemia, and so forth }\end{array}$ \\
\hline $\begin{array}{l}\text { Explanation for natural } \\
\text { anticoagulant depletion }\end{array}$ & $\begin{array}{l}\text { Decreased production of PC (warfarin); } \\
\text { increased consumption of PC and AT } \\
\text { (DIC) }\end{array}$ & $\begin{array}{l}\text { Decreased production of PC and AT (liver } \\
\text { dysfunction); increased consumption of } \\
\text { PC and AT (DIC) }\end{array}$ \\
\hline
\end{tabular}

Abbreviations: AT, antithrombin; DIC, disseminated intravascular coagulation; DVT, deep-vein thrombosis; EIA, enzyme immunoassay; HIT, heparininduced thrombocytopenia; PC, protein C; SRA, serotonin-release assay.

\section{Early-Onset and Persisting Thrombocytopenia: Coinciding HIT Is Rare}

Critically ill patients often develop early-onset thrombocytopenia that persists until death or that resolves with survival. Selleng et $\mathrm{al}^{56}$ identified 25 patients with so-called "earlyonset and persisting thrombocytopenia" out of 581 prospectively studied postcardiac surgery ICU patients, and found that the frequency of seroconversion to a positive anti-PF4/ heparin EIA did not differ from patients without persisting thrombocytopenia, indicating that the vast majority of seroconversion events are incidental and nonpathogenic. However, if a patient develops a superimposed platelet count fall within the characteristic days 5 to 10 "window" of HIT, ${ }^{56,57}$ and/or associated thrombosis, ${ }^{58}$ and plateletactivating antibodies are detectable, ${ }^{56-58}$ this would indicate "true" HIT coinciding with thrombocytopenia of critical illness. Given that only approximately 1 to $2 \%$ of postcardiac surgery patients develop HIT (i.e., a small subset of the $\sim 50-75 \%$ who form anti-PF4/heparin antibodies postcardiac surgery ${ }^{59,60}$ ), comparatively few patients would also develop HIT in the setting of early-onset and persisting thrombocytopenia.

Other HIT-Mimicking Disorders in Critically III Patients Other HIT-mimicking disorders ${ }^{53}$ include septicemia (e.g., septic endocarditis with embolic strokes), non-HIT PE-associated consumptive coagulopathy, or even catastrophic antiphospholipid syndrome complicating transition from warfarin to LMWH in a patient with antiphospholipid antibodies who becomes pregnant or requires an invasive procedure.

\section{Serological Picture of Heparin-Induced Thrombocytopenia}

\section{Platelet Serotonin-Release Assay (Washed Platelet Assay)}

The SRA was invented 30 years ago in the laboratory of Prof. John Kelton, ${ }^{18}$ and even today remains the "gold standard" for diagnosing HIT, given its high sensitivity and (relatively) high diagnostic specificity for detecting pathological HIT antibodies; in contrast, PF4-dependent immunoassays frequently detect nonpathological antibodies. $^{22}$ Our laboratory (McMaster Platelet Immunology Laboratory) performs the SRA at two pharmacological concentrations of heparin ( 0.1 and $0.3 \mathrm{IU} / \mathrm{mL} \mathrm{UFH,} \mathrm{i.e.,} \mathrm{conditions} \mathrm{where} \mathrm{HIT}$ antibody-induced platelet activation is optimal) and suprapharmacologic UFH (100 IU/mL), where HIT antibody-induced platelet activation is characteristically inhibited. ${ }^{18}$ We also measure serotonin release at $0 \mathrm{IU} / \mathrm{mL}$ UFH (i.e., buffer control); by performing this last reaction condition, we are able to identify those unusually strong HIT sera obtained from patients with delayed-onset HIT, HIT-associated DIC, persisting HIT, and so forth. Even without ongoing heparin exposure, an episode of severe HIT often reaches its peak intensity (platelet count nadir) approximately 10 to 17 days after the proximate immunizing heparin exposure. $^{4,10,30,31}$ These patients can fail alternative (nonheparin) anticoagulant therapy that is monitored using the (activated) partial thromboplastin time (PTT), due to the phenomenon of "PTT confounding" (see section, "PTT and INR confounding”). 
54 Heparin-Induced Thrombocytopenia in Critically III Patients Warkentin

Table 3 Fifteen non-HIT/non-warfarin treated patients with DIC-associated microvascular limb ischemia ${ }^{a}$

\begin{tabular}{|c|c|}
\hline Clinical or laboratory feature & Findings $^{b}$ \\
\hline Age, y & $23,43,60,66,79$ \\
\hline Sex, female & $8 / 15(53 \%)$ \\
\hline Clinical setting of acute DIC & $\mathrm{CS}=10, \mathrm{SS}=6^{\mathrm{C}}$ \\
\hline 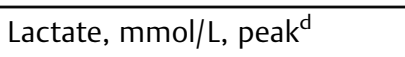 & $4.4,8.6,11.0,15.4,17.6$ \\
\hline Platelet count nadir, $\times 10^{9} / \mathrm{L}$ & $8,15,18,39,53$ \\
\hline Day of platelet count fall & $0,0,1,3,5$ \\
\hline Normoblasts, peak \% ${ }^{\mathrm{e}}$ & $0,8,26,82,98$ \\
\hline INR, peak ${ }^{f}$ & $1.8,2.4,3.1,3.9,6.1$ \\
\hline INR at limb ischemia onset & $1.6,1.9,2.4,2.5,2.6$ \\
\hline PTT at limb ischemia onset & $27,30,39,49,72$ \\
\hline Fibrinogen nadir, mg/dL & $70,118,162,261,484$ \\
\hline D-dimer, $\mu \mathrm{g} / \mathrm{L}$ FEU & Greatly elevated $^{g}$ \\
\hline ALT, U/L, peak ${ }^{\mathrm{h}}$ & $80 ; 1,100 ; 2,500 ; 5,100 ; 9,800$ \\
\hline Bilirubin, total, mg/dL, peak & $3.4,4.0,9.4,16.2,32.0$ \\
\hline ALP, U/L, peak & $98,158,211,293,960$ \\
\hline Deep-vein thrombosis (DVT) & $2 / 15(13 \%)$ \\
\hline Number of limbs affected ${ }^{k}$ & $2(n=5), 3(n=1), 4(n=9)$ \\
\hline Nonacral ischemic necrosis & $7 / 15(47 \%)$ \\
\hline
\end{tabular}

Abbreviations: ALP, alkaline phosphatase; ALT, alanine transaminase; CS, cardiogenic shock; DIC, disseminated intravascular coagulation; FEU, fibrinogen equivalent units; INR, international normalized ratio; PTT, partial thromboplastin time; SS, septic shock; U, units.

Note: The table summarizes 15 patients or patient files reviewed by the author.

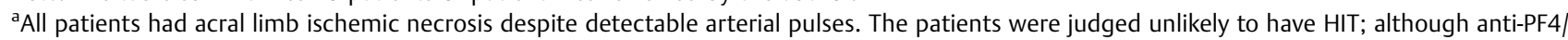
heparin antibodies were detectable in 10/15, the ElAs were generally only weakly/moderately positive (i.e., low diagnostic specificity for HIT); only 1 patient had an EIA > 2.00 units, and that patient tested negative in the serotonin-release assay. Some cases included in this table have been previously reported in detail. ${ }^{52-55}$

'Where results are shown as five data points separated by commas, these represent (in order): lowest value, Q1 (first quartile), median, Q3 (third quartile), and highest value.

'Twelve patients were postcardiac surgery; one female patient with methicillin-resistant Staphylococcus aureus endocarditis had both cardiogenic shock and septic shock; all patients had renal failure (all but one received some form of dialysis or renal replacement therapy).

dElevated lactate levels and/or acidemia was documented in all patients. Hemodynamic support with vasopressors was common, with intra-aortic balloon pumps used in five patients.

eAll but one patient reported to have circulating normoblasts (nucleated red blood cells).

${ }^{f}$ For seven patients, the peak INR occurred before onset of limb ischemia, that is, the INR was improving when limb ischemia began.

${ }^{9}$ For all evaluable patients, D-dimer exceeded the upper value for which the laboratory usually reports (e.g., $>20,000 \mu \mathrm{g} / \mathrm{L}$ FEU); for two patients who underwent further quantitation, the peak levels were 44,600 and 26,920 FEU $\mu \mathrm{g} / \mathrm{L}$.

hOut of 15, $14(93 \%)$ patients had ALT values $>\times 10$ the upper limit of normal ("acute ischemic hepatitis" or "shock liver"); the one exception $(A L T=80 \mathrm{U} / \mathrm{mL}$ ) had other factors (lower-limb DVT; placement of inferior vena cava filter) that likely contributed to acral limb ischemic necrosis. The peak ALT occurred 4 days (median; range, 1,8 ) following surgery or admission.

'The peak bilirubin occurred 8 days (median; range, 4,16 ) following surgery or admission. The percent direct (conjugated) bilirubin ranged from 54 to 95\% (median, 60\%).

${ }^{\mathrm{j} M i l d}$ elevations in ALP were seen in most patients that generally did not exceed $\times 3$ the upper limit of normal. The peak ALP occurred 16 days (median; range, 3,38 ) following surgery or admission, and typically occurred after the peak ALT.

${ }^{k}$ Symmetrical peripheral gangrene involving the lower extremities was seen in all patients. Six patients had additional involvement of upper extremities, usually involving multiple digits (bilateral in five patients).

\section{False-Positive Platelet Activation Assays in ICU Patients}

Perhaps because of elevated levels of proinflammatory proteins (e.g., fibrinogen), false-positive platelet activation assays employing a platelet aggregation endpoint-such as citrate-anticoagulated platelet-rich plasma ${ }^{61,62}$ or even washed platelets ${ }^{63}$-occur commonly in ICU patients, in comparison with the (washed platelet) SRA. A negative or weak-positive PF4-dependent EIA in such a patient points to a false-positive platelet activation assay. ${ }^{61,62}$

\section{False-Positive PF4-Dependent Immunoassays}

A far more common problem is that of false-positive EIAs. As a general rule, $50 \%$ of referred sera with detectable anti-PF4/ heparin antibodies by EIA do not contain platelet-activating antibodies, and thus represent false-positive assays. ${ }^{64,65}$ The frequency may be even higher $(70-80 \%)$ in the critically ill, $^{66,67}$ perhaps because of more frequent testing in low pretest probability situations, and possibly also because bacterial infection could trigger formation of nonpathogenic 
anti-PF4/heparin antibodies. ${ }^{35}$ Clinicians must be careful when diagnosing HIT in an ICU patient, especially when the EIA optical density (OD) value is only weakly positive (as increasing OD predicts strongly for presence of plateletactivating antibodies by SRA ${ }^{65}$ ).

\section{Prevention of Heparin-Induced Thrombocytopenia in the ICU}

\section{Reduced Risk of HIT with LMWH and Fondaparinux}

Almost 20 years ago, a substantial reduction in the risk of HIT with LMWH versus UFH was reported, ${ }^{7}$ a finding confirmed in meta-analyses. ${ }^{68,69}$ This difference in risk of HIT reflects the combination of an approximate threefold lower immunization risk and-among patients with HIT antibodies-a threefold lower risk of "breakthrough" of thrombocytopenia, among patients treated with LMWH versus UFH. ${ }^{7,8}$ Thus, the overall risk reduction of HIT with LMWH versus UFH is approximately 10 -fold (i.e., 2 vs. $0.2 \%$ frequency among postoperative patients exposed to prophylactic-dose UFH vs. LMWH for at least 7-10 days), ${ }^{68}$ and is probably at least an order of magnitude lower still with fondaparinux versus LMWH. $^{70}$ The greater capacity of UFH (vs. LMWH and fondaparinux) to form ultra-large, more immunogenic, complexes with PF4, and for these larger complexes to activate platelets, likely explains differences in HIT risk. ${ }^{3}$ Moreover, fondaparinux is much less likely than both UFH and LMWH to potentiate activation of platelets by HIT antibodies. ${ }^{71}$ The reduced risk of HIT with LMWH appears to be a drug class effect, since reduced immunization frequency has been observed with enoxaparin, ${ }^{72}$ certoparin, ${ }^{73}$ and dalteparin. ${ }^{74}$ The PROphylaxis for ThromboEmbolism in Critical Care Trial (PROTECT) trial $^{75}$ suggested that dalteparin (vs. UFH) prophylaxis reduces risk of HIT in critically ill patients.

\section{PROTECT Randomized Trial: UFH versus Dalteparin in Critically III Patients}

The PROTECT trial randomized 3,764 ICU patients in multiple medical centers to receive either dalteparin (5,000 IU oncedaily) or UFH (5,000 IU twice-daily), with the primary outcome being proximal-leg DVT (detected by compression ultrasonography). ${ }^{75}$ Secondary end points included PE and HIT (confirmed by the McMaster SRA). By intention-to-treat analysis, 12 of $1,873(0.6 \%)$ patients randomized to receive UFH developed HIT, compared with 5 of $1,873(0.3 \%)$ patients randomized to receive dalteparin (hazard ratio, 0.47 [95\% CI, $0.16-1.35] ; p=0.16$ ). These reported frequencies of HIT are consistent with the expected 0.3 to $0.5 \%$ range reported observed for HIT in critically ill patients.

\section{The HIT Substudy within the PROTECT Trial}

A prespecified per-protocol analysis (which excluded patients who already had HIT upon study enrolment) found that significantly fewer patients in PROTECT who received dalteparin versus UFH developed HIT (hazard ratio, 0.27; 95\% CI, $0.08-0.98 ; p=0.046) .{ }^{75}$ We performed a PROTECT substudy ${ }^{74}$ evaluating the potential confounding role of incidental (nonstudy) heparin exposure (including heparin administered before study enrolment), as a potential factor explaining anti-PF4/heparin immunization and/or breakthrough of thrombocytopenia. When taking such nonstudy heparin exposures into account, fewer study drug-attributable HITrelated seroconversion and breakthrough events occurred with dalteparin versus UFH $(p=0.020) .{ }^{74}$ Moreover, among patients investigated serologically for HIT, those randomized to dalteparin (vs. UFH) were half as likely to test positive for anti-PF4/heparin IgG (13 vs. $27 \% ; p<0.001) .{ }^{74}$

\section{Dalteparin for Postcardiac Surgery Thromboprophylaxis}

Based on the findings of PROTECT trial, our hospital now uses dalteparin for routine postcardiac surgery thromboprophylaxis (first dose [2,500 U], with subsequent doses 5,000 U continued until mobilization/discharge) (-Fig. 1). Observational studies of dalteparin versus UFH by Pouplard et $\mathrm{al}^{76,77}$ (-Fig. 2) suggest that the frequency of HIT could be approximately $80 \%$ lower ( 0.5 vs. $2.5 \%$ ) with dalteparin versus UFH, a finding that corresponds to the aforementioned $73 \%$ reduction (i.e., hazard ratio of 0.27 ) we observed in the per-protocol analysis reported for PROTECT trial. ${ }^{75}$

\section{Dalteparin Thromboprophylaxis in Critically III Patients}

Dalteparin was selected for study in the PROTECT trial because it was shown not to bioaccumulate when given in prophylactic doses to renally compromised patients (including patients with dialysis-dependent renal failure). ${ }^{78,79}$ This is an important consideration when choosing an agent for thromboprophylaxis in the critically ill patient population.

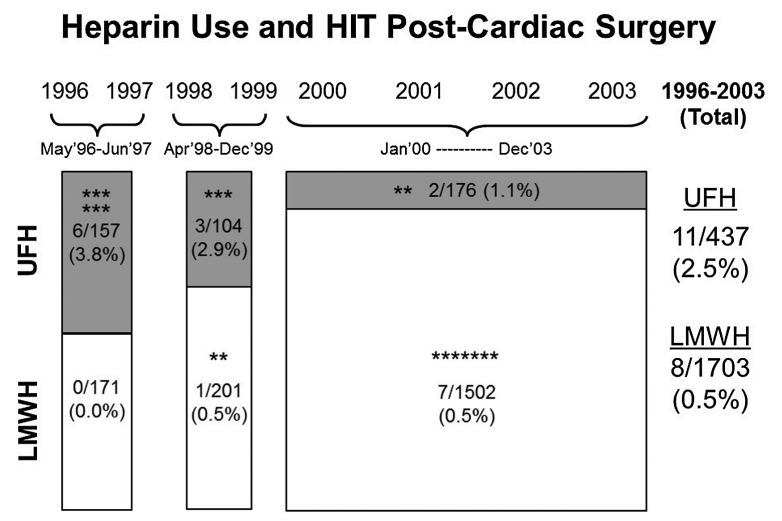

Fig. 2 Results of an observational study of the frequency of HIT in patients receiving UFH or LMWH (dalteparin) postcardiac surgery: the Tours (France) experience. The data to construct this figure are obtained from two publications by Pouplard et al. ${ }^{76,77}$ The area of each box corresponds to the number of patients treated with UFH and LMWH for each respective time period, and thus the data show increasing use of dalteparin over time. The asterisks $\left({ }^{*}\right)$ indicate the patients diagnosed with HIT (by SRA). Although the data do not represent results of a randomized trial, they do nonetheless suggest a reduced risk of HIT ( $~ 80 \%$ reduction) with dalteparin $(8 / 1,703=0.5 \%)$ versus UFH $(11 / 437=2.5 \%) ; p=0.0004$ by Fisher exact test. HIT, heparin-induced thrombocytopenia; LMWH, low-molecular-weight heparin; SRA, serotonin-release assay; UFH, unfractionated heparin. 


\section{Treatment of Heparin-Induced Thrombocytopenia in Critically Ill Patients ICU}

The treatment principles of strongly suspected (or serologically confirmed) HIT can be summarized as the “do's, don'ts, and diagnostics" 80 :

1. Three do's

a. Do stop/avoid heparin (including "flushing" intravascular catheters)

b. Do commence alternative nonheparin anticoagulant (usually in therapeutic doses)

c. Do indicate potential diagnosis of HIT in the medical record

2. Three don'ts

a. Don't give warfarin (and do give vitamin $\mathrm{K}$ if warfarin already given ${ }^{11,42}$ )

b. Don't order prophylactic platelet transfusions

c. Don't insert an inferior vena cava filter

3. Three diagnostics

a. Test for HIT antibodies

b. Test for DIC

c. Image for lower-limb DVT (as DVT is the most common complication of HIT, and its presence influences duration and intensity of anticoagulant therapy).

Although the author does not believe that heparin flushes adversely influence the clinical course of severe HIT (vis-à-vis the severe consequences of HIT antibodies that strongly activate platelets even without heparin being present), they should be avoided because of their medical-legal risk. Note also that the proscription against platelet transfusions is only a "suggestion" (i.e., a "weak" recommendation), ${ }^{11,81}$ given that (1) platelet transfusions have not been proven to be deleterious in HIT (rather, two small retrospective studies found no increased thrombotic risk ${ }^{82,83}$ ) and (2) in the ICU a non-HIT diagnosis is much more likely than HIT, and a risk-benefit assessment that includes diagnostic uncertainty would likely favor platelet transfusions for severely thrombocytopenic patients. Inferior vena cava filter use in HIT patients is often associated with DVT progression-including to critical limb ischemia and limb loss ${ }^{84}$ -and their use is not recommended.

These treatment principles should not be applied indiscriminately to the critically ill patient, for several reasons. First, thrombocytopenia in an ICU patient is attributable to HIT only in a small minority of patients; thus, the expected risk-benefit profile of therapeutic-dose, nonheparin anticoagulation in a patient with "true" HIT (high thrombosis with low bleeding risk) does not apply in a non-HIT, critically ill patient (high bleeding risk). Second, renal and hepatic dysfunctions are common in critically ill patients, which can lead to anticoagulant accumulation and increased bleeding risk. Third, coagulopathies are common in ICU, which can confound PTT-adjusted DTI therapy (see section, "PTT and INR confounding").

\section{UFH: Its Advantages in Critically III Patients}

If only approximately $1 \%$ of thrombocytopenic ICU patients have HIT, this infers that switching from heparin to a non- heparin anticoagulant will occur predominantly in non-HIT patients. But heparin is a near-ideal anticoagulant for critically ill patients: it is cleared through nonrenal, nonhepatic mechanisms, its levels can be directly quantitated (anti-factor Xa levels), and it is approved by the U.S. Food and Drug Administration for the "treatment of acute and chronic consumptive coagulopathies (disseminated intravascular coagulation)"; 85 its anticoagulant effects can be reversed quickly with protamine; it is familiar to many clinicians; and it is inexpensive. In contrast, the safety and efficacy of nonheparin anticoagulants, especially in critically ill patients, are unknown and unproven, and are problematic for use in patients with coagulopathies.

\section{PTT and INR Confounding}

Confounding of PTT- and INR-monitored anticoagulant therapy results when prolongation of these tests occurs for reasons independent of the anticoagulant being monitored. ${ }^{55}$ For example, if a patient has a baseline (preargatroban) PTT that is elevated (e.g., secondary to HIT-associated DIC), there is a real risk that the (postargatroban) PTT will be supratherapeutic, typically triggering (inappropriate) interruption/ reduction of argatroban dosing, ${ }^{86,87}$ which given argatroban's short half-life (40-50 minutes), will lead to rapid loss of anticoagulation. PTT confounding can occur with DIC, liver dysfunction, nonspecific inhibitor ("lupus anticoagulant"), or any other factor that prolongs the PTT. ${ }^{55}$

INR confounding occurs commonly during argatrobanwarfarin overlap, as argatroban itself prolongs the INR. There are reports of limb loss caused by venous limb gangrene when argatroban treatment was prematurely interrupted (because of an elevated INR) during overlap with warfarin. ${ }^{55,88}$

\section{Choice of Nonheparin Anticoagulation}

Only one anticoagulant, argatroban, is approved and currently marketed to treat HIT in the United States (lepirudin has been discontinued). Ironically, argatroban was never proven safe and effective for treating HIT, as the prospective cohort studies $^{89,90}$ used for regulatory approval did not require positive testing for HIT antibodies, and most enrolled patients likely did not have HIT, whereas most of the (historical) controls likely did have HIT, as they were identified from laboratory logs of test-positive patients. Another concern: the limb amputation rate in the argatroban-treated study patients was relatively high (13.7\%), ${ }^{11}$ perhaps reflecting the aforementioned issue of INR confounding during warfarin overlap. Further, argatroban has undergone minimal formal study in non-HIT patients, a relevant point given that comparatively few ICU patients develop HIT.

\section{Indirect (Antithrombin-dependent) Factor Xa Inhibitors}

In the author's opinion, the indirect (AT-dependent) factor Xa inhibitors, danaparoid and fondaparinux, have numerous advantages over argatroban (for review ${ }^{5,22}$ ), and thus the author has mainly treated HIT with danaparoid ${ }^{91}$ and (more recently) fondaparinux, ${ }^{92}$ with good overall outcomes. 
A major advantage of danaparoid and fondaparinux is that they are not monitored by a global coagulation test such as the PTT (thus avoiding the problem of PTT confounding); rather, if desired, drug concentrations can be measured directly (as antifactor Xa levels). However, the indirect Xa inhibitors can accumulate in renal insufficiency, and reduced dosing is appropriate in renally compromised patients. Moreover, prophylactic dose (vs. therapeutic dose) should be given in ICU patients, unless thrombosis is proven, or the clinician is reasonably sure that HIT is present (this is especially important given that danaparoid is largely ineffective when given in prophylactic doses for confirmed $\mathrm{HIT}^{93}$ ). - Appendix A summarizes my current approach for treating a patient with HIT using fondaparinux. ${ }^{94}$ Recent data ${ }^{95}$ suggest that clinicianssuch as the author-are increasingly treating patients with suspected HIT with fondaparinux, despite its off-label status for this indication.

\section{Acknowledgments}

This report received no specific grant from any funding agency in the public, commercial, or not-for-profit sectors. The author thanks Jo-Ann I. Sheppard for help in preparing the figure.

\section{References}

1 Chong BH, Pitney WR, Castaldi PA. Heparin-induced thrombocytopenia: association of thrombotic complications with heparindependent IgG antibody that induces thromboxane synthesis in platelet aggregation. Lancet 1982;2(8310):1246-1249

2 Amiral J, Bridey F, Dreyfus M, et al. Platelet factor 4 complexed to heparin is the target for antibodies generated in heparin-induced thrombocytopenia. Thromb Haemost 1992;68(1):95-96

3 Greinacher A, Pötzsch B, Amiral J, Dummel V, Eichner A, MuellerEckhardt C. Heparin-associated thrombocytopenia: isolation of the antibody and characterization of a multimolecular PF4-heparin complex as the major antigen. Thromb Haemost 1994;71(2):247-251

4 Warkentin TE. Agents for the treatment of heparin-induced thrombocytopenia. Hematol Oncol Clin North Am 2010;24(4): 755-775, ix

5 Warkentin TE. HIT paradigms and paradoxes. J Thromb Haemost 2011;9(Suppl 1):105-117

6 Warkentin TE, Kelton JG. A 14-year study of heparin-induced thrombocytopenia. Am J Med 1996;101(5):502-507

7 Warkentin TE, Levine MN, Hirsh J, et al. Heparin-induced thrombocytopenia in patients treated with low-molecular-weight heparin or unfractionated heparin. N Engl J Med 1995;332(20):1330-1335

8 Warkentin TE, Roberts RS, Hirsh J, Kelton JG. An improved definition of immune heparin-induced thrombocytopenia in postoperative orthopedic patients. Arch Intern Med 2003;163(20): 2518-2524

9 Warkentin TE. HITlights: a career perspective on heparin-induced thrombocytopenia. Am J Hematol 2012;87(Suppl 1):S92-S99

10 Warkentin TE. Clinical picture of heparin-induced thrombocytopenia. In: Warkentin TE, Greinacher A, eds. Heparin-Induced Thrombocytopenia, 5th ed. Boca Raton, FL: CRC Press; 2013:24-76

11 Warkentin TE, Greinacher A, Koster A, Lincoff AM; American College of Chest Physicians. Treatment and prevention of heparin-induced thrombocytopenia: American College of Chest Physicians Evidence-Based Clinical Practice Guidelines (8th Edition). Chest 2008;133(6, Suppl):340S-380S
12 Linkins LA, Lee DH. Frequency of heparin-induced thrombocytopenia. In: Warkentin TE, Greinacher A, eds. Heparin-Induced Thrombocytopenia, 5th ed. Boca Raton, FL: CRC Press; 2013: 110-150

13 Warkentin TE, Chong BH, Greinacher A. Heparin-induced thrombocytopenia: towards consensus. Thromb Haemost 1998;79(1): $1-7$

14 Warkentin TE, Greinacher A, Gruel Y, Aster RH, Chong BH; scientific and standardization committee of the international society on thrombosis and haemostasis. Laboratory testing for heparin-induced thrombocytopenia: a conceptual framework and implications for diagnosis. J Thromb Haemost 2011;9(12):2498-2500

15 Lo GK, Juhl D, Warkentin TE, Sigouin CS, Eichler P, Greinacher A. Evaluation of pretest clinical score ( 4 T's) for the diagnosis of heparin-induced thrombocytopenia in two clinical settings. J Thromb Haemost 2006;4(4):759-765

16 Warkentin TE, Linkins LA. Non-necrotizing heparin-induced skin lesions and the 4T's score. J Thromb Haemost 2010;8(7): 1483-1485

17 Cuker A, Gimotty PA, Crowther MA, Warkentin TE. Predictive value of the 4Ts scoring system for heparin-induced thrombocytopenia: a systematic review and meta-analysis. Blood 2012;120(20): 4160-4167

18 Sheridan D, Carter C, Kelton JG. A diagnostic test for heparininduced thrombocytopenia. Blood 1986;67(1):27-30

19 Warkentin TE, Hayward CPM, Smith CA, Kelly PM, Kelton JG. Determinants of donor platelet variability when testing for heparin-induced thrombocytopenia. J Lab Clin Med 1992;120(3): 371-379

20 Greinacher A, Michels I, Kiefel V, Mueller-Eckhardt C. A rapid and sensitive test for diagnosing heparin-associated thrombocytopenia. Thromb Haemost 1991;66(6):734-736

21 Eichler P, Budde U, Haas S, et al. First workshop for detection of heparin-induced antibodies: validation of the heparin-induced platelet-activation test (HIPA) in comparison with a PF4/heparin ELISA. Thromb Haemost 1999;81(4):625-629

22 Warkentin TE. How I diagnose and manage HIT. Hematology (Am Soc Hematol Educ Program) 2011;2011:143-149

23 Warkentin TE. Heparin-induced thrombocytopenia: pathogenesis and management. Br J Haematol 2003;121(4):535-555

24 Warkentin TE, Hayward CPM, Boshkov LK, et al. Sera from patients with heparin-induced thrombocytopenia generate platelet-derived microparticles with procoagulant activity: an explanation for the thrombotic complications of heparin-induced thrombocytopenia. Blood 1994;84(11):3691-3699

25 Greinacher A, Warkentin TE. Acquired non-immune thrombocytopenia. In: Marder VJ, Aird WC, Bennett JS, Schulman S, White GC, eds. Hemostasis and Thrombosis: Basic Principles and Clinical Practice, 6th ed. Philadelphia, PA: Lippincott Williams \& Wilkins; 2013:796-804

26 Warkentin TE, Sheppard JA, Moore JC, Cook RJ, Kelton JG. Studies of the immune response in heparin-induced thrombocytopenia. Blood 2009;113(20):4963-4969

27 Warkentin TE, Kelton JG. Temporal aspects of heparin-induced thrombocytopenia. N Engl J Med 2001;344(17):1286-1292

28 Greinacher A, Kohlmann T, Strobel U, Sheppard JA, Warkentin TE. The temporal profile of the anti-PF4/heparin immune response. Blood 2009;113(20):4970-4976

29 Warkentin TE, Sheppard JA. Serological investigation of patients with a previous history of heparin-induced thrombocytopenia who are reexposed to heparin. Blood 2014;123(16):2485-2493

30 Warkentin TE, Kelton JG. Delayed-onset heparin-induced thrombocytopenia and thrombosis. Ann Intern Med 2001;135(7): 502-506

31 Kopolovic I, Warkentin TE. Progressive thrombocytopenia after cardiac surgery in a 67-year-old man. CMAJ 2014;186(12): 929-933 
32 Warkentin TE, Makris M, Jay RM, Kelton JG. A spontaneous prothrombotic disorder resembling heparin-induced thrombocytopenia. Am J Med 2008;121(7):632-636

33 Warkentin TE, Basciano PA, Knopman J, Bernstein RA. Spontaneous heparin-induced thrombocytopenia syndrome: 2 new cases and a proposal for defining this disorder. Blood 2014;123(23): 3651-3654

34 Jay RM, Warkentin TE. Fatal heparin-induced thrombocytopenia (HIT) during warfarin thromboprophylaxis following orthopedic surgery: another example of 'spontaneous' HIT? J Thromb Haemost 2008;6(9):1598-1600

35 Krauel K, Weber C, Brandt S, et al. Platelet factor 4 binding to lipid A of Gram-negative bacteria exposes PF4/heparin-like epitopes. Blood 2012;120(16):3345-3352

36 Ketha S, Smithedajkul P, Vella A, Pruthi R, Wysokinski W, McBane R. Adrenal haemorrhage due to heparin-induced thrombocytopenia. Thromb Haemost 2013;109(4):669-675

37 Greinacher A, Farner B, Kroll H, Kohlmann T, Warkentin TE, Eichler P. Clinical features of heparin-induced thrombocytopenia including risk factors for thrombosis. A retrospective analysis of 408 patients. Thromb Haemost 2005;94(1):132-135

38 Warkentin TE. Think of HIT. Hematology (Am Soc Hematol Educ Program) 2006:408-414

39 Hong AP, Cook DJ, Sigouin CS, Warkentin TE. Central venous catheters and upper-extremity deep-vein thrombosis complicating immune heparin-induced thrombocytopenia. Blood 2003; 101(8):3049-3051

40 Warkentin TE, Elavathil LJ, Hayward CPM, Johnston MA, Russett JI, Kelton JG. The pathogenesis of venous limb gangrene associated with heparin-induced thrombocytopenia. Ann Intern Med 1997; 127(9):804-812

41 Srinivasan AF, Rice L, Bartholomew JR, et al. Warfarin-induced skin necrosis and venous limb gangrene in the setting of heparininduced thrombocytopenia. Arch Intern Med 2004;164(1):66-70

42 Warkentin TE. Should vitamin K be administered when HIT is diagnosed after administration of coumarin? J Thromb Haemost 2006;4(4):894-896

43 Kelton JG, Warkentin TE. Heparin-induced thrombocytopenia: a historical perspective. Blood 2008;112(7):2607-2616

44 Warkentin TE, Pai M, Cook RJ. Intraoperative anticoagulation and limb amputations in patients with immune heparin-induced thrombocytopenia who require vascular surgery. J Thromb Haemost 2012;10(1):148-150

45 Warkentin TE, Bernstein RA. Delayed-onset heparin-induced thrombocytopenia and cerebral thrombosis after a single administration of unfractionated heparin. N Engl J Med 2003;348(11): 1067-1069

46 Warkentin TE. Heparin-induced skin lesions. Br J Haematol 1996; 92(2):494-497

47 Warkentin TE, Greinacher A. Heparin-induced anaphylactic and anaphylactoid reactions: two distinct but overlapping syndromes. Expert Opin Drug Saf 2009;8(2):129-144

48 Warkentin TE, Hirte HW, Anderson DR, Wilson WEC, O'Connell GJ, Lo RC. Transient global amnesia associated with acute heparininduced thrombocytopenia. Am J Med 1994;97(5):489-491

49 Hillis C, Warkentin TE, Taha K, Eikelboom JW. Chills and limb pain following administration of low-molecular-weight heparin for treatment of acute venous thromboembolism. Am J Hematol 2011;86(7):603-606

50 Rauova L, Hirsch JD, Greene TK, et al. Monocyte-bound PF4 in the pathogenesis of heparin-induced thrombocytopenia. Blood 2010; 116(23):5021-5031

51 Selleng K, Warkentin TE, Greinacher A. Heparin-induced thrombocytopenia in intensive care patients. Crit Care Med 2007;35(4): 1165-1176

52 Warkentin TE. Heparin-induced thrombocytopenia in critically ill patients. Crit Care Clin 2011;27(4):805-823, v
53 Warkentin TE, Cuker A. Differential diagnosis of heparin-induced thrombocytopenia and scoring systems. In: Warkentin TE, Greinacher A, eds. Heparin-Induced Thrombocytopenia, 5th ed. Boca Raton, FL: CRC Press; 2013:77-109

54 Siegal DM, Cook RJ, Warkentin TE. Acute hepatic necrosis and ischemic limb necrosis. N Engl J Med 2012;367(9):879-881

55 Warkentin TE. Anticoagulant failure in coagulopathic patients: PTT confounding and other pitfalls. Expert Opin Drug Saf 2014;13(1): 25-43

56 Selleng S, Malowsky B, Strobel U, et al. Early-onset and persisting thrombocytopenia in post-cardiac surgery patients is rarely due to heparin-induced thrombocytopenia, even when antibody tests are positive. J Thromb Haemost 2010;8(1):30-36

57 Selleng S, Selleng K, Wollert HG, et al. Heparin-induced thrombocytopenia in patients requiring prolonged intensive care unit treatment after cardiopulmonary bypass. J Thromb Haemost 2008;6(3):428-435

58 Warkentin TE, Moore JC, Vogel S, Sheppard JA, Warkentin NI, Eikelboom JW. The serological profile of early-onset and persisting post-cardiac surgery thrombocytopenia complicated by "true" heparin-induced thrombocytopenia. Thromb Haemost 2012; 107(5):998-1000

59 Warkentin TE, Sheppard JA, Horsewood P, Simpson PJ, Moore JC, Kelton JG. Impact of the patient population on the risk for heparininduced thrombocytopenia. Blood 2000;96(5):1703-1708

60 Warkentin TE, Sheppard JI, Sun JCJ, Jung H, Eikelboom JW. AntiPF4/heparin antibodies and venous graft occlusion in postcoronary artery bypass surgery patients randomized to postoperative unfractionated heparin or fondaparinux thromboprophylaxis. J Thromb Haemost 2013;11(2):253-260

61 Trehel-Tursis V, Louvain-Quintard V, Zarrouki Y, Imbert A, Doubine S, Stéphan F. Clinical and biologic features of patients suspected or confirmed to have heparin-induced thrombocytopenia in a cardiothoracic surgical ICU. Chest 2012;142(4):837-844

62 Warkentin TE. Heparin-induced thrombocytopenia in the ICU: a transatlantic perspective. Chest 2012;142(4):815-816

63 Selleng S, Selleng K, Friesecke S, et al. Prevalence and clinical implications of anti-PF4/heparin antibodies in intensive care patients: a prospective observational study. J Thromb Thrombolysis 2014(e-pub ahead of print)

64 Lo GK, Sigouin CS, Warkentin TE. What is the potential for overdiagnosis of heparin-induced thrombocytopenia? Am J Hematol 2007;82(12):1037-1043

65 Warkentin TE, Sheppard JI, Moore JC, Sigouin CS, Kelton JG. Quantitative interpretation of optical density measurements using PF4-dependent enzyme-immunoassays. J Thromb Haemost 2008; 6(8):1304-1312

66 Levine RL, Hergenroeder GW, Francis JL, Miller CC, Hursting MJ. Heparin-platelet factor 4 antibodies in intensive care patients: an observational seroprevalence study. J Thromb Thrombolysis 2010; 30(2):142-148

67 Berry C, Tcherniantchouk O, Ley EJ, et al. Overdiagnosis of heparininduced thrombocytopenia in surgical ICU patients. J Am Coll Surg 2011;213(1):10-17, discussion 17-18

68 Martel N, Lee J, Wells PS. Risk for heparin-induced thrombocytopenia with unfractionated and low-molecular-weight heparin thromboprophylaxis: a meta-analysis. Blood 2005;106(8): 2710-2715

69 Warkentin TE, Sheppard JA, Sigouin CS, Kohlmann T, Eichler P, Greinacher A. Gender imbalance and risk factor interactions in heparin-induced thrombocytopenia. Blood 2006;108(9): 2937-2941

70 Warkentin TE, Davidson BL, Büller HR, et al. Prevalence and risk of preexisting heparin-induced thrombocytopenia antibodies in patients with acute VTE. Chest 2011;140(2):366-373

71 Warkentin TE, Cook RJ, Marder VJ, et al. Anti-platelet factor 4/ heparin antibodies in orthopedic surgery patients receiving 
antithrombotic prophylaxis with fondaparinux or enoxaparin. Blood 2005;106(12):3791-3796

72 Warkentin TE, Sheppard JA, Moore JC, Moore KM, Sigouin CS, Kelton JG. Laboratory testing for the antibodies that cause heparininduced thrombocytopenia: how much class do we need? J Lab Clin Med 2005;146(6):341-346

73 Lubenow N, Hinz P, Thomaschewski S, et al. The severity of trauma determines the immune response to PF4/heparin and the frequency of heparin-induced thrombocytopenia. Blood 2010;115(9): 1797-1803

74 Warkentin TE, Sheppard JA, Heels-Ansdell D, et al; Canadian Critical Care Trials Group; Australian and New Zealand Intensive Care Society Clinical Trials Group. Heparin-induced thrombocytopenia in medical surgical critical illness. Chest 2013;144(3): 848-858

75 Cook D, Meade M, Guyatt G, et al; PROTECT Investigators for the Canadian Critical Care Trials Group and the Australian and New Zealand Intensive Care Society Clinical Trials Group. Dalteparin versus unfractionated heparin in critically ill patients. N Engl J Med 2011;364(14):1305-1314

76 Pouplard C, May MA, Iochmann S, et al. Antibodies to platelet factor 4-heparin after cardiopulmonary bypass in patients anticoagulated with unfractionated heparin or a low-molecularweight heparin : clinical implications for heparin-induced thrombocytopenia. Circulation 1999;99(19):2530-2536

77 Pouplard C, May MA, Regina S, Marchand M, Fusciardi J, Gruel Y. Changes in platelet count after cardiac surgery can effectively predict the development of pathogenic heparin-dependent antibodies. Br J Haematol 2005;128(6):837-841

78 Douketis J, Cook DJ, Meade M, et al. Canadian Critical Care Trials Group. Prophylaxis against deep vein thrombosis in critically ill patients with severe renal insufficiency with the low-molecularweight heparin dalteparin: the DIRECT study. Arch Intern Med 2008;168(16):1805-1812

79 Rabbat CG, Cook DJ, Crowther MA, et al. Dalteparin thromboprophylaxis for critically ill medical-surgical patients with renal insufficiency. J Crit Care 2005;20(4):357-363

80 Warkentin TE. Heparin-induced thrombocytopenia: diagnosis and management. Circulation 2004;110(18):e454-e458

81 Linkins LA, Dans AL, Moores LK, et al; American College of Chest Physicians. Treatment and prevention of heparin-induced thrombocytopenia: Antithrombotic Therapy and Prevention of Thrombosis. Chest 2012; 141(2, Suppl):e495S-e530S

82 Hopkins CK, Goldfinger D. Platelet transfusions in heparin-induced thrombocytopenia: a report of four cases and review of the literature. Transfusion 2008;48(10):2128-2132

83 Refaai MA, Chuang C, Menegus M, Blumberg N, Francis CW. Outcomes after platelet transfusion in patients with heparin- induced thrombocytopenia. J Thromb Haemost 2010;8(6): 1419-1421

84 Greinacher A, Warkentin TE. Treatment of heparin-induced thrombocytopenia: an overview. In: Warkentin TE, Greinacher A, eds. Heparin-Induced Thrombocytopenia, 5th ed. Boca Raton, FL: CRC Press; 2013:315-355

85 Heparin Sodium, Injection, USP. Available at: www.hospira.com/ Images/EN-3339_81-92293_1.pdf. Accessed December 16, 2014

86 Linkins LA, Warkentin TE. Heparin-induced thrombocytopenia: real-world issues. Semin Thromb Hemost 2011;37(6): 653-663

87 Smythe MA, Forsyth LL, Warkentin TE, Smith M, Sheppard JI, Shannon F. Progressive, fatal thrombosis associated with heparin-induced thrombocytopenia following cardiac surgery despite "therapeutic" anticoagulation with argatroban: potential role for PTT and ACT confounding. J Thorac Cardiovasc Anesth 2014(e-pub ahead of print)

88 Smythe MA, Warkentin TE, Stephens JL, Zakalik D, Mattson JC. Venous limb gangrene during overlapping therapy with warfarin and a direct thrombin inhibitor for immune heparin-induced thrombocytopenia. Am J Hematol 2002;71(1):50-52

89 Lewis BE, Wallis DE, Berkowitz SD, et al; ARG-911 Study Investigators. Argatroban anticoagulant therapy in patients with heparin-induced thrombocytopenia. Circulation 2001;103(14): 1838-1843

90 Lewis BE, Wallis DE, Leya F, Hursting MJ, Kelton JG; Argatroban915 Investigators. Argatroban anticoagulation in patients with heparin-induced thrombocytopenia. Arch Intern Med 2003; 163(15):1849-1856

91 Lubenow N, Warkentin TE, Greinacher A, et al. Results of a systematic evaluation of treatment outcomes for heparin-induced thrombocytopenia in patients receiving danaparoid, ancrod, and/ or coumarin explain the rapid shift in clinical practice during the 1990s. Thromb Res 2006;117(5):507-515

92 Warkentin TE, Pai M, Sheppard JI, Schulman S, Spyropoulos AC, Eikelboom JW. Fondaparinux treatment of acute heparin-induced thrombocytopenia confirmed by the serotonin-release assay: a 30-month, 16-patient case series. J Thromb Haemost 2011;9(12): 2389-2396

93 Farner B, Eichler P, Kroll H, Greinacher A. A comparison of danaparoid and lepirudin in heparin-induced thrombocytopenia. Thromb Haemost 2001;85(6):950-957

94 Warkentin TE. Fondaparinux: does it cause HIT? Can it treat HIT? Expert Rev Hematol 2010;3(5):567-581

95 Schindewolf M, Steindl J, Beyer-Westendorf J, et al. Frequent offlabel use of fondaparinux in patients with suspected acute heparin-induced thrombocytopenia (HIT)-findings from the GerHIT multi-centre registry study. Thromb Res 2014;134(1):29-35 
60 Heparin-Induced Thrombocytopenia in Critically III Patients Warkentin

Appendix A Diagnostic and therapeutic approach to HIT: highlighting use of fondaparinux

\begin{tabular}{|c|}
\hline A. Baseline (pretreatment) diagnostic evaluation \\
\hline CBC/differential with blood film, including assessment of nucleated red blood cells (normoblasts), reticulocyte count, and red cell fragments ${ }^{a}$ \\
\hline Coagulation tests ${ }^{\mathrm{b}}$ : PT (INR), ${ }^{\mathrm{c}}$ PTT, ${ }^{\mathrm{d}}$ fibrinogen, ${ }^{\mathrm{e}}$ fibrin D-dimer (quantitative ${ }^{\mathrm{f}}$ ), and/or other fibrin-specific marker(s) (e.g., fibrin monomer), $A \mathrm{~T}^{g}$ \\
\hline Chemistry tests: creatinine, $\mathrm{LDH}^{\mathrm{h}}$ (compare with simultaneously measured AST, ALT, and CK), bilirubin \\
\hline Lower-limb ultrasound for DVT (routine) $)^{i}$ \\
\hline Upper-limb ultrasound for DVT (if upper-limb swelling') \\
\hline B. Serial laboratory assessment (at least once-daily) \\
\hline CBC (follow normoblast count, if elevated) \\
\hline Coagulation tests ${ }^{\mathrm{b}}$ : PT (INR), ${ }^{\mathrm{c}}$ PTT, ${ }^{\mathrm{d}}$ fibrinogen, ${ }^{\mathrm{e}}$ fibrin D-dimer (quantitative ${ }^{\mathrm{f}}$ ) and/or other fibrin-specific marker(s), $\pm A T^{g}$ \\
\hline $\begin{array}{l}\text { Antifactor Xa level calibrated for fondaparinux (drawn at } \sim 0600 \mathrm{~h} \text { each morning), especially if there is renal dysfunction (e.g., estimated creatinine } \\
\text { clearance }<60 \mathrm{~mL} / \mathrm{min} / 1.73 \mathrm{~m}^{2} \text { ) }\end{array}$ \\
\hline \pm creatinine (if there is renal dysfunction) \\
\hline \pm LDH (if initially elevated and hemolysis is suspected) \\
\hline \pm AST, ALT, and bilirubin (if hepatic dysfunction is suspected) \\
\hline \pm CK (if ischemic limb injury is suspected) \\
\hline C. Therapeutic-dose fondaparinux regimen for treatment of (strongly suspected or confirmed) acute HIT, including HIT-associated thrombosis \\
\hline First dose (afternoon/evening $): 7.5 \mathrm{mg}$ (or $10 \mathrm{mg}^{\mathrm{l}}$ ) by subcutaneous injection ${ }^{\mathrm{m}}$ for patient weighing $50-100 \mathrm{~kg}^{\mathrm{n}}$ \\
\hline Second and subsequent doses (morning at $\sim 0800 \mathrm{~h}$ ): $7.5 \mathrm{mg}$ by subcutaneous injection \\
\hline Dosing adjustments for renal failure \\
\hline $\begin{array}{l}\text { Do not reduce the first dose or two; subsequently, reduce daily dose to } 5 \text { or } 2.5 \mathrm{mg} \text {, depending on the extent of renal dysfunction, and results of } \\
\text { antifactor Xa levels (if available) }\end{array}$ \\
\hline Target (trough) anti-Xa level (fondaparinux) is $0.60-1.00$ anti-Xa U/mL ${ }^{\mathrm{P}}$ \\
\hline AT concentrates: give $\sim 1,000 \mathrm{U}$ every 12 hours (if AT depletion is documented and fondaparinux is being used for anticoagulation) ${ }^{g}$ \\
\hline D. Prophylactic-dose regimen for fondaparinux ${ }^{q}$ \\
\hline $2.5 \mathrm{mg}$ by subcutaneous injection ${ }^{r}$ \\
\hline E. Freeze residual plasma samples \\
\hline Facilitate retrospective analysis \\
\hline
\end{tabular}

Abbreviations: ALT, alanine transaminase; AT, antithrombin; CBC, complete blood count; DIC, disseminated intravascular coagulation; DVT, deep-vein thrombosis; FEU fibrinogen equivalent units; HIT, heparin-induced thrombocytopenia; LDH, lactate dehydrogenase; PT (INR), prothrombin time (international normalized ratio); PTT, (activated) partial thromboplastin time.

${ }^{a}$ Normoblastemia, reticulocytosis, and, less often, red cell fragments can be seen in severe HIT-associated DIC.

${ }^{\text {b} T h e ~ a u t h o r ~ f o l l o w s ~ s e r i a l ~ c o a g u l a t i o n ~ m a r k e r s, ~ e s p e c i a l l y ~ i n ~ p a t i e n t s ~ w i t h ~ s e v e r e ~ H I T-a s s o c i a t e d ~ D I C, ~ w h e r e ~ e f f e c t i v e ~ a n t i c o a g u l a t i o n ~ s h o u l d ~ r e s u l t ~ i n ~}$ decrease in INR, increase in fibrinogen, and decrease in fibrin D-dimer levels.

'An otherwise unexplained elevated INR in a patient with HIT suggests possibility of HIT-associated DIC.

${ }^{\mathrm{d}}$ An elevated PTT increases risk of "PTT confounding" with use of PTT-adjusted anticoagulant, for example, argatroban or bivalirudin.

${ }^{\mathrm{e}}$ As HIT usually occurs in postoperative patients, an elevated fibrinogen level is expected; thus, a fibrinogen level that is low $(<1.5 \mathrm{~g} / \mathrm{L}[<150 \mathrm{mg} / \mathrm{dL}])$ or low normal $(1.5-2.5 \mathrm{~g} / \mathrm{L}[150-250 \mathrm{mg} / \mathrm{dL}])$ can be seen in severe HIT-associated DIC.

f In our laboratory, fibrin D-dimer is routinely reported up to $4,000 \mathrm{FEU} \mu \mathrm{g} / \mathrm{mL}$ (higher values are reported as $>4,000 \mathrm{FEU} \mu \mathrm{g} / \mathrm{mL}$ ), but on request can be further quantitated up to $20,000 \mathrm{FEU} \mu \mathrm{g} / \mathrm{mL}$; serial D-dimers are useful in assessing response to therapy.

${ }^{g} \mathrm{AT}$ is measured at baseline, and followed serially if there is HIT-associated DIC (fondaparinux is an AT-dependent factor Xa inhibitor).

${ }^{h} \mathrm{LD}$ or $\mathrm{LDH}$ is a marker of hemolysis, and elevated levels are sometimes seen in severe HIT-associated DIC. Initial assessment of LDH should be compared with liver enzymes (ALT, AST) and muscle enzymes (AST, CK), as an isolated increase in LDH is most specific for hemolysis. 'Approximately $50 \%$ of patients with HIT are found to have lower-limb DVT.

jUpper-limb DVT occurs in $~ 10 \%$ of patients with HIT and is invariably associated with concurrent/recent use of an intravascular catheter.

${ }^{\mathrm{k}} \mathrm{As}$ HIT is often recognized by reduced platelet counts, and as routine CBCs are generally drawn in the morning in hospitalized patients, treatment for HIT is thus frequently started in the afternoon or evening.

' $10 \mathrm{mg}$, rather than $7.5 \mathrm{mg}$, may be appropriate even for a 50-100 kg patient if HIT is judged very severe (e.g., with overt DIC), or if initial dose is given in the morning and, therefore, a 20 to 24 -hour interval before next (morning) dose is anticipated.

mIntravenous (i.v.) injection can be considered if immediate anticoagulation is desired. If given i.v., flush the line afterward, or administer the fondaparinux in 25 to $50 \mathrm{~mL}$ normal saline over 3 to 5 minutes.

"Dosing decreased to $5 \mathrm{mg}$ if body weight $<50 \mathrm{~kg}$ and increased to $10 \mathrm{mg}$ if body weight $>100 \mathrm{~kg}$.

${ }^{\circ}$ The rationale for administering second and subsequent doses in the morning-even if the first dose was given in the preceding afternoon or eveningis that it will help achieve early therapeutic levels of anticoagulation (since there will usually be $<20$-hour interval between the first two doses); in addition, it will facilitate determining trough plasma anticoagulant levels (if desired) by drawing antifactor Xa levels at the morning blood draw. ${ }^{\mathrm{P}} \mathrm{A}$ target trough drug level of 0.6 to 1.0 anti-Xa U/mL is currently being used by the author; although the anti-Xa level (drawn at $\sim 0600 \mathrm{~h}$ ) will not be available at the time that the fondaparinux injection is given $(\sim 0800 \mathrm{~h})$, the goal of serial anti-Xa levels is to assess whether drug accumulation that warrants subsequent dose reduction is occurring.

9Low-dose (prophylactic-dose) fondaparinux regimen may be appropriate if: (1) patient has low (or intermediate) probability for acute HIT and (2) no thrombosis is evident; or (3) for various other settings of prophylactic-dose anticoagulation, for example, patient with history of previous HIT who requires postoperative thromboprophylaxis.

'Assumes normal renal function. 